\title{
EI SOPA: un congreso internacional que trabaja por una verdadera democracia cultural en el ámbito rural
}

Sabah Walid, Juanjo Pulido | UNDERGROUND Arqueología Patrimonio \& Gente

URL de la contribución <www.iaph.es/revistaph/index.php/revistaph/article/view/4433>

\section{RESUMEN}

El SOPA es un congreso diferente, innovador en formatos y gobernanza, cuyo objetivo principal es educar en lo común, que sitúa en los márgenes territoriales -rural-y que quiere afianzarse como comunidad de aprendizajes. Pero como colectivo errante es un proceso en constante construcción, por lo que sin estructuras fijas, el SOPA se va adaptando a lo que su comunidad necesita, desde la escucha y el respeto de los tiempos y los territorios, por sus patrimonios y sus memorias.

\section{Palabras clave}

Comunidad rural | Congreso | Espacios rurales | Gestión comunitaria | Memoria colectiva | Patrimonio rural | SOPA | UNDERGROUND Arqueología Patrimonio \& Gente | 


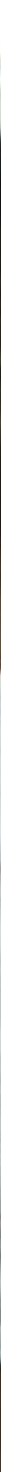

Presentación del seminario "Mujer Rural y Memorias Comunes" en Canicab, Yucatán/Congreso SOPA17, Mérida+Canicab, México | foto Congreso SOPA, que ha proporcionado todas las imágenes que ilustran este artículo 


\section{MOTIVO Y CONTEXTO}

Hace ya algunos años, allá por 2012, desde la colectiva UNDERGROUND Arqueología Patrimonio \& gente, vimos la necesidad de crear un entorno amable en el que trabajar sobre lo que nosotras entendíamos como socialización del patrimonio cultural. Podríamos haberlo hecho de forma genérica, pero pensábamos que era importante centrarnos en un contexto tan frágil como es el rural, con un patrimonio en una situación de desamparo administrativo y mediático en favor de un patrimonio urbano que se piensa más beneficioso a nivel económico. Sabemos que esta fragilidad no está vinculada principalmente al patrimonio, que posiblemente sea el último de los problemas del rural, y que ese desamparo es global pero pensamos que es importante que desde cada ámbito se trabaje con un objetivo común: la resistencia.

El medio rural contiene gran parte del patrimonio conservado y en peligro de desaparición, entendiendo éste como el conjunto de patrimonio construido e inmaterial de todas las cronologías y que forma parte de la historia y las narraciones locales. Si últimamente vemos cómo la situación actual del campo está en momentos críticos, sobre todo en las áreas periféricas, más alejadas de las grandes ciudades, o de los centros patrimoniales más importantes o más turistificados, creemos que es el momento de apostar por nuevas formas de hacer.

Las nuevas políticas culturales están basadas en lo que se conoce como "democratización cultural", es decir, facilitar el acceso de la ciudadanía (que no de la comunidad, pero ese es otro debate) a los distintos campos de la cultura: cine, arte, artes escénicas, literatura y, por extensión, al patrimonio y a los museos. Por este motivo, dependiendo de los intereses de cada momento, son unas u otras las disciplinas y agentes "democratizadores", al igual que son unos $u$ otros los elementos patrimoniales que merecen ser protegidos, recuperados o dados a conocer, incluyendo las distintas declaratorias que

Miembros del Club La Paz de la Tercera Edad en la sesión de presentación de proyectos. Congreso SOPA13, Malpartida de Cáceres, España

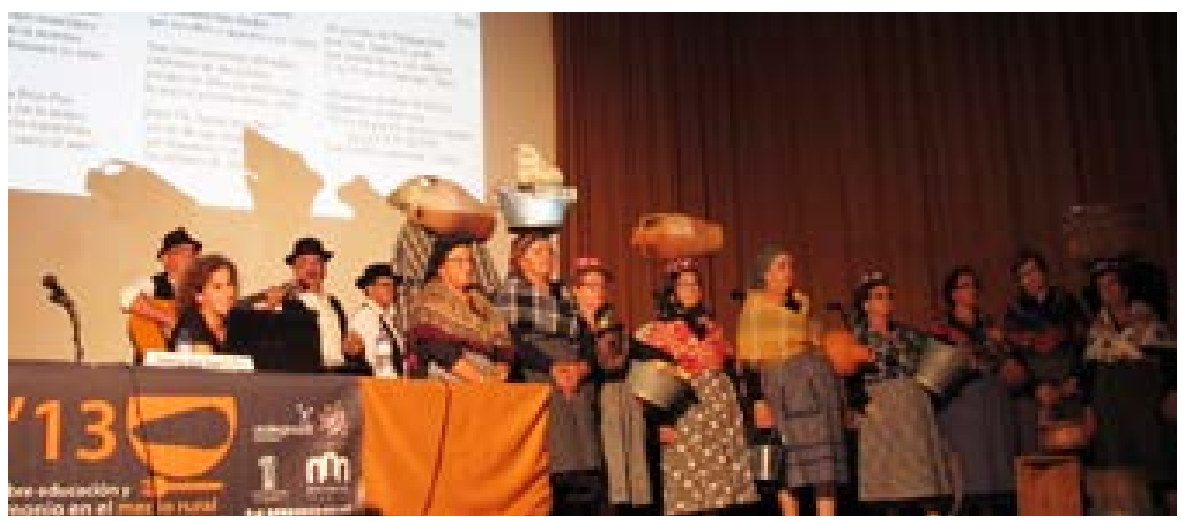


parecen ser la panacea pero que en muchas ocasiones producen el efecto contrario (PULIDO; WALID, 2019: 111). Y es importante incidir en este punto, porque es crucial a la hora de valorar, no ya si son viables o sostenibles este tipo de procesos, sino si merece la pena intentarlo. Desde las estrategias de la democratización de la cultura, esta es entendida como un bien colectivo que debe ponerse a disposición de toda la ciudadanía, a iniciativa de la administración, donde el papel de la comunidad es la de mera espectadora. Hay una cosa clara, y es que la gente es el fin último de los procesos culturales, y son varias las formas en las que ésta se relaciona con esos procesos. No obstante, en la mayoría de los casos encontramos que esos procesos se plasman en una participación de la ciudadanía sobre un producto cultural concreto, que se presenta en bien de la sociedad, aunque esa sociedad no es integrada en la creación del discurso ni en el posterior diálogo. Se trata de un público que ni siquiera espera poder entrar en esos procesos, con lo cual al final termina comportándose tal y como se les presenta, como público. Y no público como ente genérico, sino muchas veces como ente numérico o cuantificable que sirve para evaluar la rentabilidad de los proyectos culturales, los espacios musealizados o las supuestas políticas participativas, muy de moda en estos momentos de cambio, por parte de las administraciones.

Así, como acabamos de comentar, recursos, gestión, proyectos, ámbitos territoriales y "públicos" son elegidos arbitrariamente, manteniendo la coyuntura del panem et circenses y dificultando la construcción de una masa crítica, más todavía en el entorno rural, que tenga la capacidad de proponer sus propios procesos culturales y que estos sean escuchados y apoyados, compartiendo responsabilidades tanto la comunidad como la administración, fomentando así el pluralismo y la interculturalidad. Y por eso, este fue unos de los principales motivos por el que iniciamos esta andadura: trabajar por una verdadera democracia cultural.

El segundo motivo, porque las políticas de puesta en valor, en la mayor parte de los casos, se ciñen exclusivamente a los grandes conjuntos históricos o a yacimientos arqueológicos de entidad, hecho entendible al ser los motores de la generación de recursos turísticos, y por lo tanto económicos, de un territorio determinado (o cualquier patrimonio valorado de forma arbitraria por cualquier otro motivo). No obstante, se dejan al margen a muchos otros lugares con un patrimonio que posiblemente no sea relevante dentro de esas directrices, pero sí para sus comunidades y para el resto de la sociedad. En este sentido, tanto el ámbito educativo como el de la gestión del patrimonio tienen un papel fundamental a la hora de inculcar en esa sociedad los valores necesarios para propiciar la autogestión de sus propios recursos patrimoniales. $Y$ ahí nace la necesidad de hacer confluir en un momento y espacio concreto todas las personas, proyectos, recursos y reflexiones vinculadas a un territorio como es el rural y a un aspecto cultural como es el del patrimonio y la memoria colectiva.

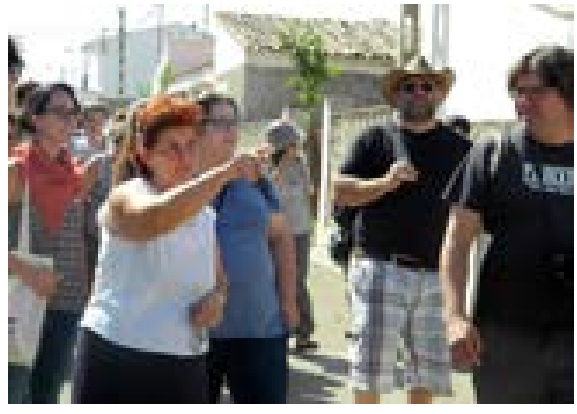

Visita, organizada por la asociación de vecinas, por las calles del pueblo de colonización del Docenario durante el seminario"Patrimonios del Conflicto". Congreso SOPA16, Zalamea de la Serena, España

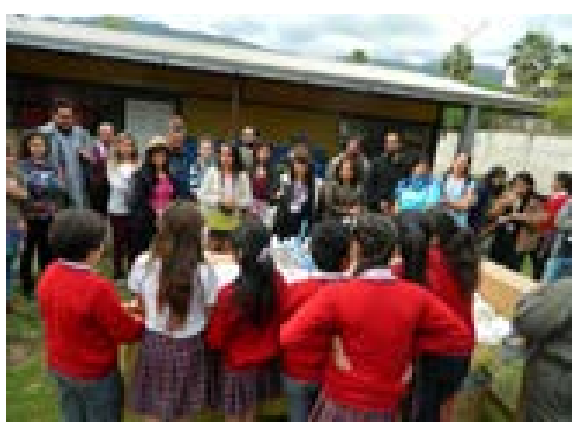

SOPA Chiquito: Presentación de proyectos medioambientales en la Escuela Lo Narváez durante el seminario "Patrimonio Natural: Procesos Comunitarios de Gestión y Defensa". Congreso SOPA18, Olmué, Chile 


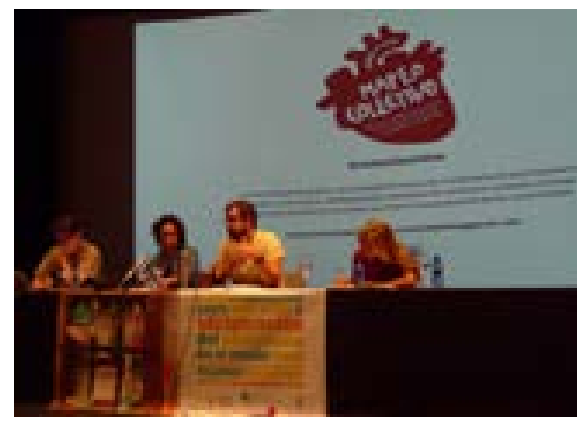

Conferencia del colectivo Iconoclasistas (Argentina) sobre mapeo colectivo. Congreso SOPA14 Celanova, España

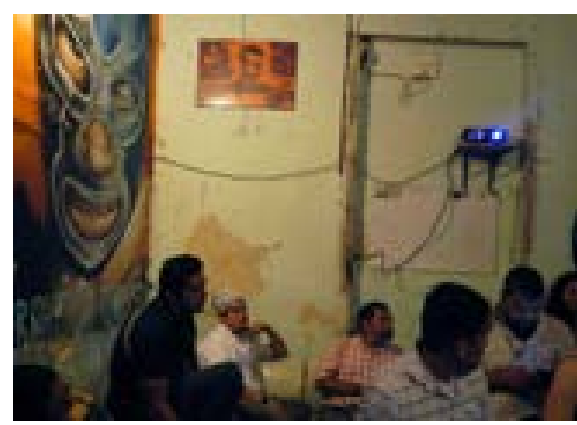

Barferencias en la pulquería La Casa de Todxs, Mérida, Yucatán. Congreso SOPA17, Mérida+Canicab, México

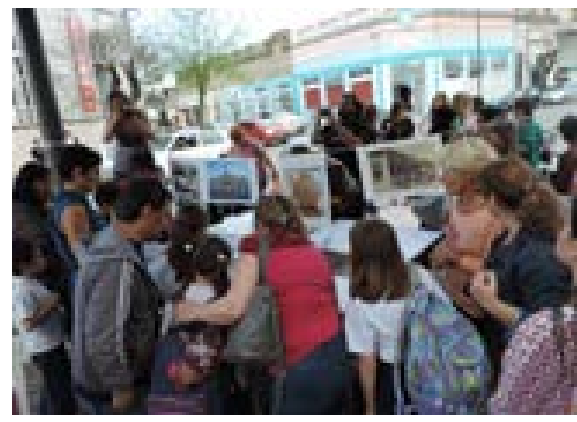

Dinámica participativa sobre el patrimonio local. Congreso SOPA15, Benito Juárez, Argentina

\section{EL FORMATO DEL SOPA: CONGRESO INTERNACIONAL DE SOCIALIZACIÓN DEL PATRIMONIO EN EL MEDIO RURAL}

Ya teníamos el motivo y el contexto, pero necesitábamos el formato. El hecho de elegir el de congreso en lugar de otro más dinámico o alternativo responde a que, en aquel momento, gran parte de los equipos y proyectos que trabajaban sobre patrimonio cultural estaban vinculados, directa o indirectamente, tanto con el mundo científico como con el académico, ya que es un foro en el que se encuentran cómodos a la hora de presentar resultados y experiencias. Por ello hemos venido respetando el formato de presentación de ponencias, comunicaciones y pósteres, al uso.

Entonces, ¿qué hicimos para adecuar el SOPA al proceso que estábamos construyendo? Desde el punto de vista del formato, empezamos a introducir nuevos agentes, nuevos lenguajes y nuevas herramientas que pudieran adaptarse al desarrollo de acciones vinculadas al patrimonio rural y sobre todo, que permitieran crear procesos creativos abiertos (WALID; PULIDO, 2018: 53). Muchas de esas herramientas tenían su origen en estrategias de trabajo colaborativo (no relacionadas específicamente con el patrimonio, pero sí con otros ámbitos sociales), sobre todo en el espacio urbano.

También le dimos especial protagonismo al territorio cercano a la sede en la que se celebra cada edición, y nos apropiamos de nuevos espacios y escenarios de comunicación y relación. Los bares, los mercados, las plazas, las calles, los colegios... sin que estos lugares desmerezcan la calidad de los distintos mensajes y discursos.

Pero, sobre todo, pretendíamos innovar en lo participativo. Porque estábamos implicando a la comunidad en todo el proceso, tanto en la planificación como en la ejecución. Porque las comunidades quieren que todo el mundo se dé cuenta de que ellas son las que han mantenido vivo el patrimonio rural. Porque la comunidad rural también quiere la voz para que no siempre se hable de ella cuando en la mayoría de los casos podría hablar por sí misma y generar conocimiento en lugar de tener siempre que recibirlo. Y también, muy importante para nosotras, porque en cada edición del SOPA pueden generarse otras herramientas, otras propuestas y otras acciones que posibiliten procesos y conexiones de gentes, saberes y afectos.

En definitiva, nos encontramos ante un espacio híbrido académico/informal en el que se presentan proyectos, instituciones y colectivos que trabajan el patrimonio rural en comunidad, que fomentan la recuperación de conocimientos y memorias colectivas de pueblos y comunidades. Ante un espacio de debate y reflexión sobre cómo se trabaja con la comunidad, en visibilizar esa cultura, los problemas que nos encontramos para fomentar la participación, para la organización de eventos y proyectos, o la gestión de recursos 
para fomentar el desarrollo cultural del medio rural. Y todo ello para favorecer una nueva visión de los espacios rurales, más innovadores, más proactivos y más implicados con su entorno y con su memoria, dando a conocer experiencias tanto regionales como nacionales e internacionales.

Sin embargo, el aspecto del que más nos sentimos orgullosas es el del SOPA como un entorno de afectos y de cuidados. Como espacio en construcción colaborativa, entendemos que una de nuestras tareas es visibilizar los cuidados como práctica inclusiva y grupal, donde el respeto sea ejercido por todas la personas incorporando en sus prácticas la mediación entre iguales, la empatía y el encuentro comunitario. Desde estas premisas entendemos que los cuidados transcienden a las personas, incorporando el entorno y las formas de vida de las diferentes comunidades, así como cuidando la acogida de todas las participantes y facilitando su inmersión en el grupo, y sobre todo, trabajando los conflictos como aprendizajes compartidos.

Como espacio "en obra", la comunidad SOPA va incorporando las decisiones que se han ido generando en los diferentes encuentros, propiciando entornos más amables. Para ello adaptamos, en la medida de lo posible, las necesidades que van surgiendo de cuidado de niñas y niños, de lactancia (para aquellas personas que lo necesiten durante su participación en el congreso), asambleas de resolución de conflictos, espacios violeta...

\section{TRAYECTORIA}

EI SOPA nace en 2013 como parte del proyecto CINETÍNERE: cine itinerante por la recuperación social del patrimonio en el medio rural, un ciclo viajero de cine sobre patrimonio rural promovido desde el Ayuntamiento de Malpartida de Cáceres, y que gestionamos desde UNDERGROUND Arqueología Patrimonio \& Gente. El proyecto, financiado por las Ayudas a Corporaciones Locales para actividades culturales que fomenten la comunicación cultural, correspondientes al año 2012, convocadas por la Secretaría de Cultura del Ministerio de Educación, Cultura y Deporte, nos llevó durante el verano de ese año por distintos puntos del rural de Galicia, Asturias, Castilla y León y Extremadura, a trabajar con diferentes comunidades para evaluar el impacto de los territorios y sus habitantes en la gestión de su patrimonio cultural. A la vuelta del viaje, teníamos previsto en el proyecto la celebración de una jornada de puesta en común de los resultados en la propia Malpartida de Cáceres, pero pensábamos que toda esa información se quedaría ahí y no tendría mucho más recorrido.

Durante la ruta, coincidimos con agentes, comunidades y colectivos que trabajaban en la misma línea que nosotras, y pensábamos que sería ideal crear un punto de encuentro para trabajar y compartir. Y de ahí surgió el SOPA. 
Al principio, aunque lo habíamos creado como congreso internacional, pensábamos que solo participarían personas o entidades de España, o como mucho de Portugal (era un formato y un tema nuevo, o poco trabajado). Nada más lejos de la realidad, en esa primera edición en Malpartida de Cáceres, nos encontramos con gentes de España y Portugal, sí, pero también de Argentina, Colombia, México, Francia, Italia e incluso de Azerbaiyán. Rápidamente comprendimos que el interés por trabajar en la gestión comunitaria del patrimonio era un tema global, que aunque no estaba todavía desarrollado en nuestro país sí contaba con un gran recorrido en Latinoamérica (no solo con el patrimonio sino en cualquier contexto social), y que teníamos que mirar al otro lado del atlántico. Así, después de la edición de 2014 en Celanova, Galicia (territorio, el gallego, referente para nosotras en ese momento y todavía ahora), decidimos llevar el SOPA a Argentina. Ahí le cambió la vida al congreso y a nosotras mismas.

En las dos primeras ediciones en España, mientras intentábamos recolocar el formato, las acciones y los discursos, la participación de la comunidad se centró en formar parte de algunos de los procesos. A partir de Argentina, empezó a definirse su implicación definitiva. En la edición del SOPA 2015, celebrado en la localidad de Benito Juárez, en la provincia de Buenos Aires, teníamos como referentes locales a Silvina Irouléguy y a Luján Marino, que asistieron al primer SOPA en Malpartida de Cáceres. Desde un año antes a las fechas del congreso, movilizaron a numerosas personas e instituciones de la comunidad local para que formaran parte de la organización. No solo consiguieron "convencerlas" cada una desde su voluntad y su mayor o menor compromiso, sino que desde la comunidad se "exigió", al faltar todavía muchos meses para la realización del congreso, empezar a trabajar y generar actividades para darle repercusión al SOPA y movilizar a más personas. De ahí surgieron los "preSOPAS", acciones relacionadas con cualquier faceta del patrimonio y de su entorno (rutas, charlas, talleres de gastronomía o folclore, exposiciones, etc.), que a partir de ahí han ido celebrándose no solo en las sedes sucesivas del congreso, sino también en otros territorios e incluso países en los que, o bien ya se había celebrado el SOPA o iban a ser la próxima sede. Viendo cómo fue el inicio del SOPA argentino, es fácil imaginarse cómo fue el final. Desde entonces, cuando se celebra en Benito Juárez cualquier actividad relacionada con el patrimonio siempre la vinculan al congreso.

También, desde esa edición de 2015, desde el equipo del SOPA decidimos la celebración cada año de un seminario sobre un tema específico, en el que trabajar de forma intensiva y organizando de forma paralela diversas actividades complementarias relacionadas con cada tema. En estos seminarios se han tratado temas como la "rurubania" (Benito Juárez, Argentina), el "patrimonio del conflicto" (Zalamea de la Serena, España), el papel de "la mujer como sostenedora del patrimonio cultural" 
(Mérida+Canicab, México), el "patrimonio natural y los procesos de gestión y defensa" (Olmué, Chile) o el de las "memorias migrantes", para la edición de este año en Colombia.

Lo más sencillo a la hora de elegir el lugar de celebración de un congreso es una ciudad con un gran auditorio, unas buenas infraestructuras hoteleras, unos buenos accesos (por carretera, ferrocarril o cercana a un aeropuerto) y con espacios con múltiples recursos tecnológicos.

No obstante, si estamos hablando de un congreso sobre el rural, en el que se trabaja la problemática del patrimonio en el rural, lo más justo es que se desarrollara en el rural, a sabiendas que el esfuerzo logístico es mayor ya que en ocasiones es difícil conseguir todos esos medios de los que dispone el medio urbano. Pero nuestro compromiso con el territorio nos hace apostar, en la medida de lo posible, por este ámbito con todas sus consecuencias, aunque en alguna edición, como es el caso del SOPA17 en Yucatán (Mérida, México), tuviéramos que adaptarnos, por necesidades puntuales, a un espacio plenamente urbano (aunque para la celebración del seminario nos desplazamos a Canicab, una localidad plenamente rural).

El SOPA es un espacio político. Desde el momento en el que apostamos por una forma de trabajar, de entender el patrimonio y sus contextos, las implicaciones y los apoyos fluctúan. Muchas han sido (y son) las instituciones públicas y privadas que de alguna forma $u$ otra han formado parte de la organización y desarrollo del SOPA en estas seis ediciones. Desde ayuntamientos, diputaciones, universidades, centros de investigación, museos, a entidades sociales, como centros de atención a personas con otras capacidades, escuelas, fundaciones, pasando por todo tipo de empresas, desde medios de comunicación locales, a restaurantes y bares (para la cesión de espacios sobre todo), o empresas vinculadas al patrimonio y a la cultura. Pero realmente, la fuerza del SOPA viene de los colectivos, de la gente. Asociaciones culturales, folclóricas, de mujeres, medioambientales, feministas, de personas mayores, cada una de ellas con sus demandas, sus necesidades, sus conflictos y sus luchas dentro del rural. Y si implicamos a esas asociaciones y colectivos en nuestro proceso, que menos que nosotras desde el SOPA nos impliquemos también en los suyos.

No sabemos qué futuro le deparará al SOPA. Como comentábamos anteriormente, es un proyecto "en obra". Es un proyecto en continuo cambio que ya no se centra únicamente en los días del congreso, que se trabaja globalmente desde distintos territorios y ámbitos. De ahí pueden surgir cosas nuevas, o no; puede desaparecer o diluirse o fortalecerse. Lo que está claro es que es un proceso que permitirá conocer e implementar nuevas formas en las que comunidades, patrimonios y territorios se interrelacionen en conseguir un rural más real, más palpable y más sostenible. 


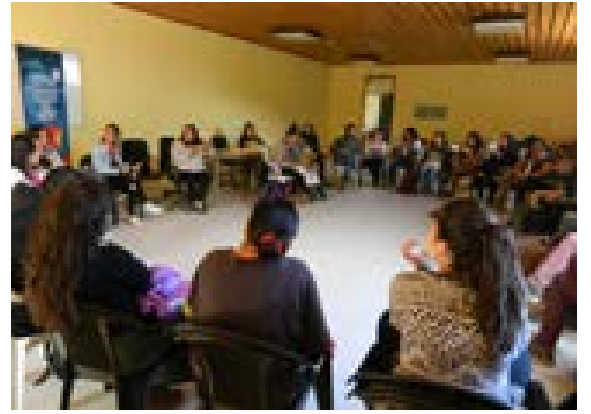

Sesión de trabajo en la comunidad rural La Dormida, durante el seminario "Patrimonio Natural: Procesos Comunitarios de Gestión y Defensa". Congreso SOPA18, Olmué, Chile

\section{RETOS}

Desde nuestro papel como organizadoras del SOPA, somos conscientes de la dificultad que supone llevar a cabo este tipo de estrategias a nivel global organizando el congreso cada año en un lugar distinto, porque, lo queramos o no, siempre vamos a estar supeditadas a los cambios constantes en las políticas públicas o, en este caso, culturales y patrimoniales de los distintos países y territorios. La postura crítica del SOPA escuece y lo sabemos. Por ello, precisamos de la implicación de aquellas instituciones que desde su posición de poder apuesten por el cambio de coyuntura. Y si esto no fuera posible, por lo menos desde el punto de vista de los agentes culturales o patrimoniales, independientemente de que sus funciones y competencias estén asociadas al papel que se les otorgue desde las políticas públicas, su protagonismo en este contexto puede depender de su propia iniciativa social (GARRIDO; HERNÁNDEZ, 2014: 65). Esto sería lo ideal, y sabemos que es un reto sumamente ambicioso, pero al igual que en otros contextos sociales, la comunidad siempre tiene la voluntad de sacar adelante sus procesos, y si es con el acompañamiento de otros agentes, mejor.

En este sentido, en el caso del SOPA, a lo largo de su recorrido, y queremos entender que fruto de esa nueva sensibilidad, ha recibido varios reconocimientos. El hecho de que las instituciones públicas, relacionadas directa o indirectamente con el patrimonio, decidan apoyar o valorar nuevas formas de gestión, o de vinculación entre el patrimonio y la comunidad, posibilitará un escenario más propicio para la implementación de procesos que permitan mejorar la situación del patrimonio cultural, y en este caso, el localizado en el medio rural. Así, en 2013 se concedió el Premio Comunidad Sostenible 2013 por parte de UNESCO Extremadura a Malpartida de Cáceres por el proyecto Cinetínere del que surge el SOPA; en 2015, en Argentina, el SOPA obtuvo la Declaración de Interés Legislativo por parte de la Honorable Cámara de Diputados de la Provincia de Buenos Aires; la Declaración de Interés Educativo por la Dirección General de Cultura y Educación de la Provincia de Buenos Aires; y el Auspicio y Declaración de Interés Cultural por parte del Ministerio de Cultura de la Nación; y, en 2017, el primer premio en los Premios de Urbanismo y Ordenación del Territorio de la Comunidad Autónoma de Extremadura, en la modalidad Resolución de Problemáticas Revalorización de Recursos Urbanísticos y/o Territoriales, por parte de la Consejería de Medio Ambiente y Rural, Políticas Agrarias y Territorio de la Junta de Extremadura.

\section{RETORNOS}

Como hemos comentado, una de las "desventajas" de la itinerancia del SOPA es que cada año empezamos desde cero. Con un evento asentado 
en un mismo territorio, es más fácil ir consolidando implicaciones y apegos, y así generar un proceso más amplio más allá del congreso. No obstante, nuestro objetivo es la absorción, tanto por nuestra parte como por la del resto de actores, de diversas realidades que nos nutran de nuevas estrategias, herramientas y formas de afrontar las distintas problemáticas del rural y su patrimonio para, posteriormente, poder implementarlas en otras ediciones, y por qué no, en nuestros propios proyectos.

Aún así, el paso efímero del SOPA por las distintas sedes provoca una serie de retornos que, si son bien utilizados por los agentes locales, pueden contribuir, por una parte, para las localidades, a obtener un valor añadido en la implementación y desarrollo de proyectos relacionados con el patrimonio local; también ganar un reconocimiento por parte de la comunidad al facilitarle un acceso abierto y participativo en los procesos de gestión patrimonial; y a un reconocimiento externo como municipio implicado tanto en su patrimonio como en permitir otras formas de generación de riqueza a partir del trabajo de la comunidad. Y por otra parte, en cuanto a las comunidades, les beneficiará en el conocimiento de nuevas estrategias de gestión social del patrimonio para aplicarlas, por ejemplo, en trabajar por un turismo cultural de calidad vinculado al patrimonio y a la identidad productiva, en el desarrollo de actividades formativas ligadas a productos culturales específicos para el municipio o para promover la participación comunitaria en el diseño de líneas estratégicas para el desarrollo local en cualquier ámbito, además del patrimonial.

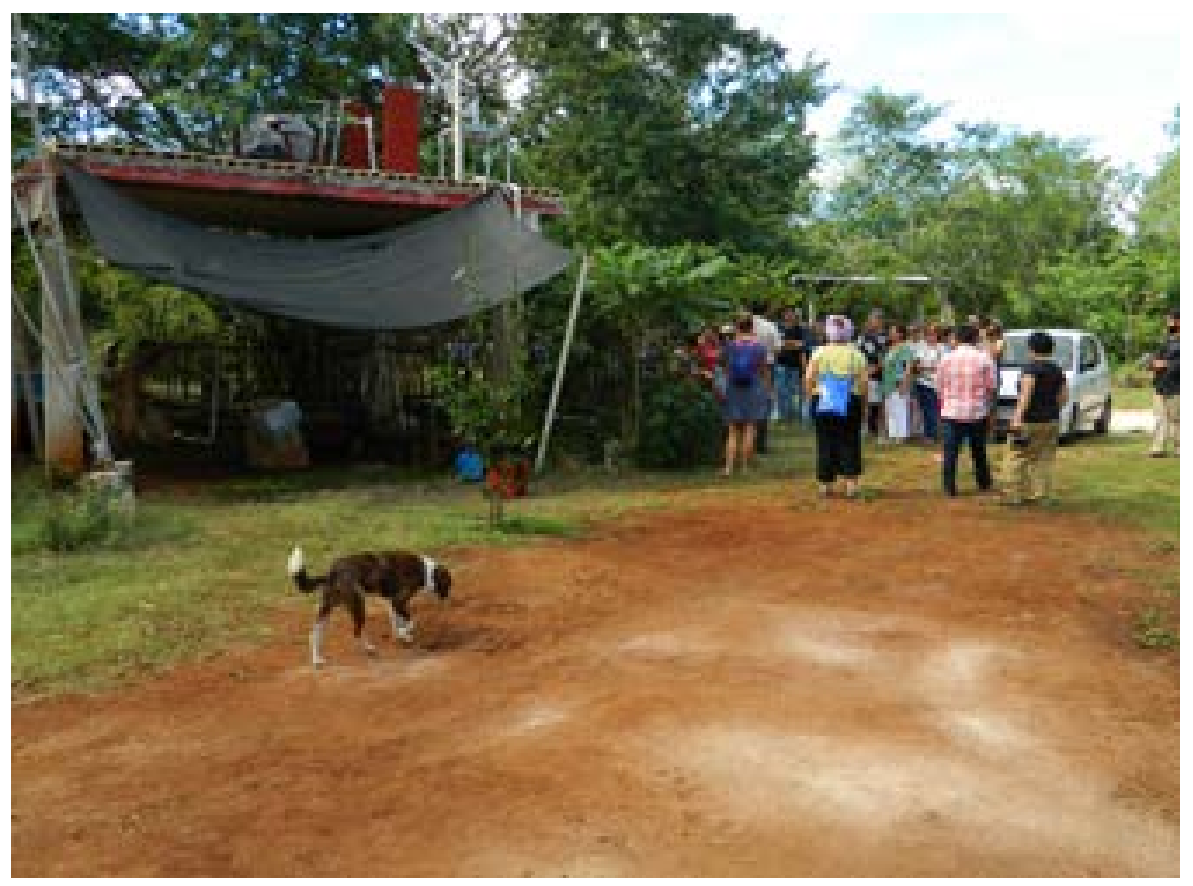




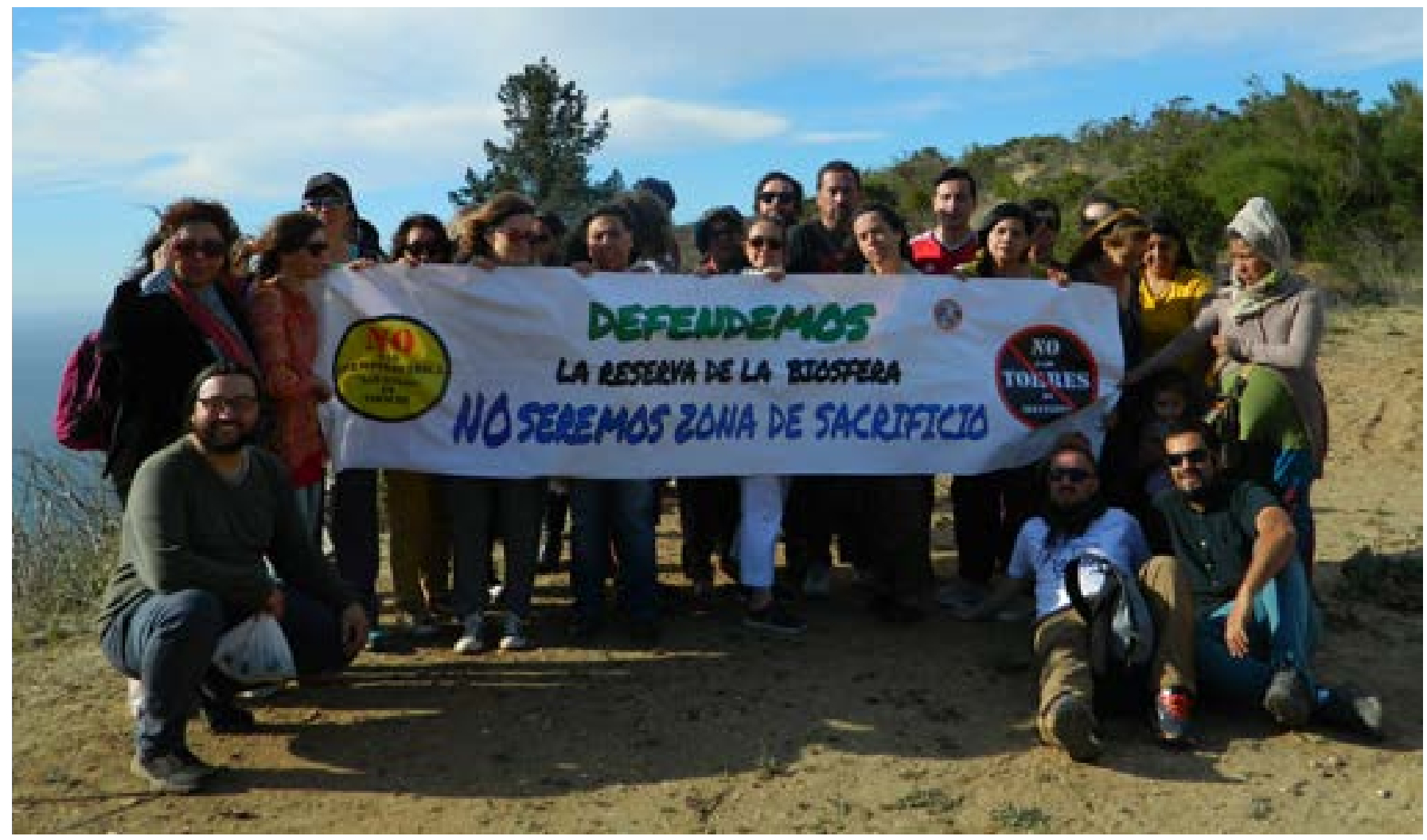

Apoyo de la comunidad SOPA a las acciones de defensa de la naturaleza en el entorno del Parque Nacional de La Campana. Congreso SOPA18, Olmué, Chile

\section{FINAL}

El SOPA ha puesto sobre la mesa cómo trabajar desde la gestión y educación patrimonial tradicional, dentro de los discursos dominantes, y la incorporación de nuevos actores sumando a las comunidades en espacios donde antes no estaban. Esto ha supuesto la apuesta por ocupar los espacios públicos y la incorporación de otros lenguajes que crean nuevas narrativas mucho más ricas, justas y no homogeneizantes, en las que la sociedad civil no solo actúa como un parapeto contrapoder, sino que apuesta por la colaboración no jerarquizada y por estrategias decoloniales para la construcción de esas narrativas. Es ahí donde entran conceptos como el de patrimonio expandido, que nace desde nuestro acercamiento a la Escuela Expandida (DÍAZ; FREIRE, 2012), convirtiendo la creación de conocimiento patrimonial en un acto colaborativo y compartido.

Desde el SOPA hemos creado comunidad, hemos facilitado la conexión entre proyectos, territorios y personas, y hemos posibilitado la generación de procesos de colaboración entre colectivos, asociaciones y entidades de todo el mundo para el desarrollo de propuestas que propicien una mayor visibilidad del trabajo realizado en facilitar la gestión comunitaria del patrimonio rural. 


\section{BIBLIOGRAFÍA}

- DÍAZ, R.; FREIRE, J. (ed.) (2012) Educación Expandida. Barcelona: ZEMOS98, 2012

- GARRIDO ARROYO, M. C.; HERNÁNDEZ CARRETERO, A. M. (2014) El patrimonio cultural: una propuesta particiativa. Tejuelo, n. ${ }^{0} 19,2014$, pp. 62-75

- PULIDO, J.; WALID, S. (2019) Los museos como entidades de cohesión y dinamización del patrimonio y la memoria colectiva a través de la gestión comunitaria transfronteriza. Ebvrobriga, X, 2019, pp. 111-116

- WALID SBEINATI, S.; PULIDO ROYO, J. (2018) El Congreso SOPA como herramienta de visibilización y cocreación de nuevos procesos patrimonializadores desde la comunidad rural. En GALÁN PÉREZ, A.; PARDO SAN GIL, D. (coord.) (2018) Las profesiones del patrimonio cultural. Competencias, formación y transferencia del conocimiento: reflexiones y retos en el Año Europeo del Patrimonio Cultural 2018. Madrid: ACRE; GE-IIC, 2018, pp. 50-55 